Article

\title{
Factors Influencing $\mathrm{PM}_{2.5}$ Concentrations in the Beijing-Tianjin-Hebei Urban Agglomeration Using a Geographical and Temporal Weighted Regression Model
}

\author{
Qiuying $\mathrm{Li}^{1}$, Xiaochun $\mathrm{Li}^{2}$ and Hongtao $\mathrm{Li}^{3, *}$ \\ 1 Institute of Shandong Academy of Social Sciences, Jinan 250002, China; skyliqiuying@foxmail.com \\ 2 Institute of Geographic Sciences and National Resources Research, Chinese Academy of Sciences, \\ Beijing 100101, China; lixc.20s@igsnrr.ac.cn \\ 3 Foreign Environmental Cooperation Center, Ministry of Ecology and Environment, Beijing 100035, China \\ * Correspondence: li.hongtao@fecomee.org.cn
}

Citation: Li, Q.; Li, X.; Li, H. Factors Influencing $\mathrm{PM}_{2.5}$ Concentrations in the Beijing-Tianjin-Hebei Urban Agglomeration Using a Geographical and Temporal Weighted Regression

Model. Atmosphere 2022, 13, 407.

https://doi.org/10.3390/

atmos 13030407

Academic Editor: Jim Kelly

Received: 6 January 2022

Accepted: 15 February 2022

Published: 2 March 2022

Publisher's Note: MDPI stays neutral with regard to jurisdictional claims in published maps and institutional affiliations.

Copyright: () 2022 by the authors. Licensee MDPI, Basel, Switzerland. This article is an open access article distributed under the terms and conditions of the Creative Commons Attribution (CC BY) license (https:/ / creativecommons.org/licenses/by/ $4.0 /)$.

\begin{abstract}
Air pollution is the environmental issue of greatest concern in China, especially the $\mathrm{PM}_{2.5}$ pollution in the Beijing-Tianjin-Hebei urban agglomeration (BTHUA). Based on sustainable development, it is of interest to study the spatiotemporal distribution of $\mathrm{PM}_{2.5}$ and its influencing mechanisms. This study reveals the temporal evolution and spatial clustering characteristic of $\mathrm{PM}_{2.5}$ pollution from 2015 to 2019, and quantifies the drivers of its natural and socioeconomic factors on it by using a geographical temporal weighted regression model. Results show that $\mathrm{PM}_{2.5}$ concentrations reached their highest level in 2015 before decreasing in the following years. The monthly averages all present a U-shaped change trend. Relative to the traditional high concentrations in the northern part of the BTHUA domain in 2015, the gap in pollution between the north and south has reduced since 2018. The obvious spatial heterogeneity was demonstrated in both the strength and direction of the variables. This study may help identify reasons for high $\mathrm{PM}_{2.5}$ concentrations and suggest appropriate targeted control and prevention measures.
\end{abstract}

Keywords: $\mathrm{PM}_{2.5}$ pollution; U-shaped change trend; influencing mechanism; BTHUA; GTWR

\section{Introduction}

Many countries and regions in the world have long suffered from air pollution, which results in various problems such as climate change, greenhouse trapping, and environmental degradation. Among all air pollutants, fine particulate matter $\left(\mathrm{PM}_{2.5}\right.$; particles less than $2.5 \mu \mathrm{m}$ in aerodynamic diameter) is strongly associated with adverse health effects. Epidemiological studies have shown connections between $\mathrm{PM}_{2.5}$ and various diseases such as asthma, cardiovascular disorders, respiratory infections, and even premature death [1-3]. As one of the largest economies and the fastest-developing countries globally, China is confronted with severe air pollution. Among the most critical environmental issues people face, air pollution has become a global concern, and the regional governance of $\mathrm{PM}_{2.5}$ has received much attention in recent years $[4,5]$.

It is widely recognized that the concentrations of $\mathrm{PM}_{2.5}$ are closely related to meteorological conditions and human economic activities. Many studies have focused on the characteristics and contributing factors for $\mathrm{PM}_{2.5}$. Natural factors include rainfall, temperature, wind speed, and relative humidity [6-8]. Socioeconomic factors including urbanization [9,10], economic development [11,12], transportation [13,14], energy consumption [15], and foreign direct investment [16,17] have played crucial roles in air pollution analysis. For instance, Lou (2016) identified six factors associated with $\mathrm{PM}_{2.5}$ accumulations: urbanization, industry share, construction level, urban expansion, income disparity, and private vehicles [18]. Zhan et al. (2018) concluded that natural factors constitute the main impetus in the deterioration of air pollution, rather than socioeconomic factors [19]. Liu 
(2020) examined the relationships between $\mathrm{PM}_{2.5}$ pollution and factors and indicated that socioeconomic factors such as economic growth, population density, and urban built-up areas led to increases in $\mathrm{PM}_{2.5}$ concentrations [20].

Several approaches have been applied to analyze the driving factors of $\mathrm{PM}_{2.5}$, including the application of least squares regression, a geographical detector, structural decomposition analysis, and a geographically weighted regression model [21,22]. Akbal (2021) utilized hybrid deep learning methodology to model particulate matter (PM) of Ankara City [23]. Akdi (2021) adopted a periodogram-based time series methodology to investigate monthly $\mathrm{PM}_{2.5}$ of Paris for the period between January 2000 and December 2019 [24].

On the whole, existing research has produced crucial advancements and laid a firm foundation for this study area. However, the existing findings on the key factors affecting $\mathrm{PM}_{2.5}$ have failed to identify the individual and potential contributing factors unique to a distinct region and have not considered regional temporal and spatial heterogeneity individually [19]. To fill the clear gap that exists in our knowledge, this study makes two main contributions compared with previous studies. First, we applied a geographical and temporal weighted regression model (GTWR) to conduct this study. The GTWR captures the spatial variations in regression coefficients for different research units and allows the spatiotemporal disparities to be calculated separately. Second, six types of influence degree were divided according to the parameter results of the GTWR model, and their intensities of driving forces are discussed respectively.

This paper presents the changes in $\mathrm{PM}_{2.5}$ concentration characteristics and the spatial variations in the key driving factors of $\mathrm{PM}_{2.5}$ in the BTHUA from 2015 to 2019. A geographical and temporal weighted regression model was applied to identify and analyze the spatiotemporal differentiation of influencing factors, which quantifies their individual effects specific to each study unit. The series of findings resulting from this paper can greatly benefit policymakers who seek to appropriately formulate targeted, refined, and differentiated air quality improvement measures in the BTHUA area.

\section{Materials and Methods}

\subsection{Study Area}

The Beijing-Tianjin-Hebei urban agglomeration (BTHUA) lies in the center of China's Circum-Bohai-Sea Region, with a population of 109.8 million in 2019. It covers 134,735 square kilometers, accounting for $7.79 \%$ of China's population and $1.9 \%$ of China's territory. In 2019, the BTHUA produced 8447 billion Yuan of GDP, accounting for $8.56 \%$ of the national GDP and ranking third among China's 20 urban agglomerations. Its GDP per capita increased to 77,000 Yuan in 2019. The urbanization of BTHUA reached $62.13 \%$, higher than the average national rate. The BTHUA is usually administratively divided into three distinct regions: Beijing, Tianjin, and Hebei, which include the cities of Shijiazhuang, Baoding, Langfang, Cangzhou, Qinhuangdao, Tangshan, Zhangjiakou, and Chengde. The spatial range data for this studied region is obtained from China National Natural Resources Department Standard Map Service System Pipe Network (http://bzdt.ch.mnr.gov.cn/, accessed on 5 January 2022) (Figure 1). 


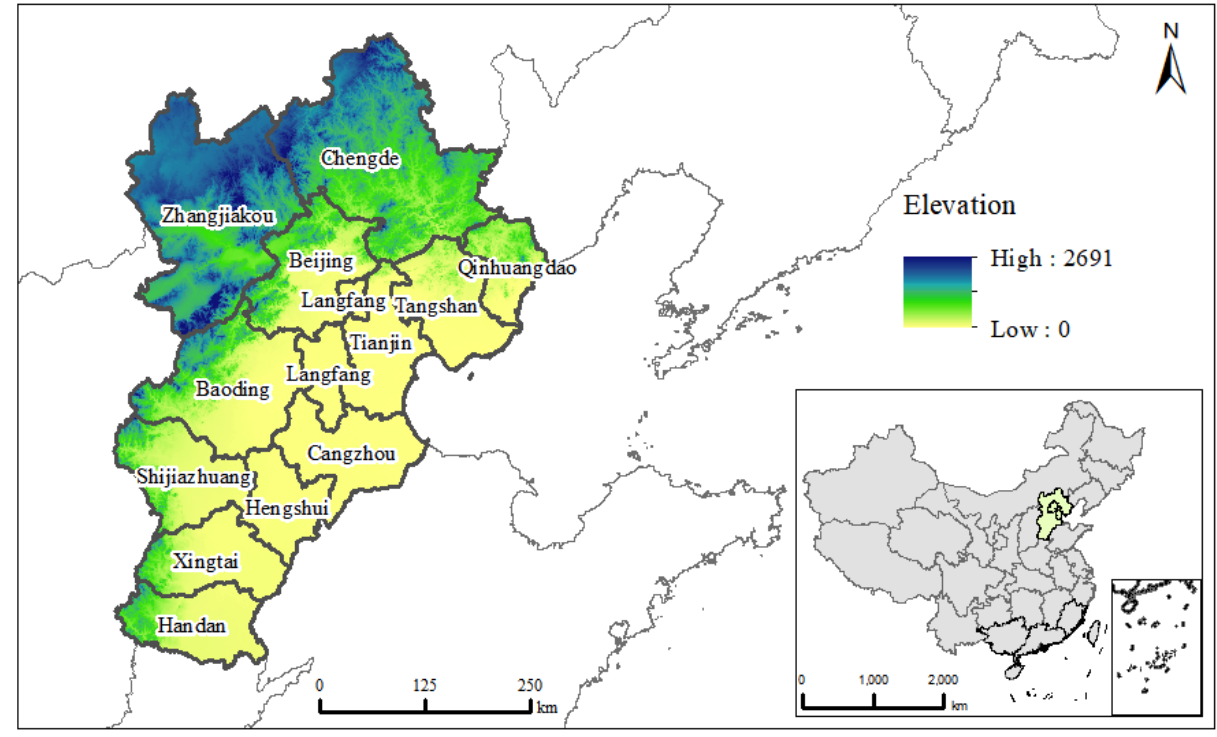

Figure 1. Location and range of Beijing-Tianjin-Hebei urban agglomeration.

\subsection{Natural Factors}

Consistent with previous research, the natural conditions explored in this study include four factors: rainfall (R), wind speed (WS), relative humidity $(\mathrm{RH})$, and temperature (T). Rainfall is a fundamental natural factor known to negatively impact $\mathrm{PM}_{2.5}$ concentrations in Chinese cities [25], consistent also with research results from Nagasaki, Japan [26]. Using Seoul as a study area, Park (2021) found that wind speed was essential to $\mathrm{PM}_{2.5}$ concentrations [27]. Pateraki (2012) found a significant correlation between relative humidity and $\mathrm{PM}_{2.5}$ [28], consistent with the results of Tai (2010) [29]. Temperature is known to be sensitive to all pollutant concentrations [30]. In particular, Yang (2017) found a negative relationship between temperature and $\mathrm{PM}_{2.5}$ concentrations [31]. Table 1 shows the statistical information for each of the variables related to $\mathrm{PM}_{2.5}$.

Table 1. Statistical summary of the variables.

\begin{tabular}{cccccc}
\hline Variable Definition & Symbol & Max & Min & Mean & Std. Dev. \\
\hline Rainfall $(\mathrm{mm})$ & $\mathrm{R}$ & 8483.42 & 4881.53 & 6083.97 & 744.85 \\
Wind speed $(\mathrm{m} / \mathrm{s})$ & $\mathrm{WS}$ & 2.59 & 1.88 & 2.25 & 0.21 \\
Relatively humidity $(\%)$ & $\mathrm{RH}$ & 64.38 & 50.17 & 57.90 & 3.19 \\
$\quad$ Temperature $\left({ }^{\circ} \mathrm{C}\right)$ & $\mathrm{T}$ & 13.87 & 9.18 & 12.31 & 1.30 \\
$\begin{array}{c}\text { Economic development } \\
\text { (billion yuan) }\end{array}$ & $\mathrm{GDP}$ & 3537.13 & 122.00 & 623.14 & 813.96 \\
$\begin{array}{c}\text { Industrial structure (\%) } \\
\text { Technology innovation } \\
\quad \text { (billion yuan) }\end{array}$ & $\mathrm{IS}$ & 0.57 & 0.16 & 0.41 & 0.10 \\
$\begin{array}{c}\text { Foreign Direct Investment } \\
\quad \text { (billion dollar) }\end{array}$ & $\mathrm{TI}$ & 223.36 & 0.01 & 13.75 & 37.96 \\
$\begin{array}{c}\text { Environmental regulation } \\
\text { (ton } / \text { billion yuan) }\end{array}$ & $\mathrm{FDI}$ & 24.33 & 0.01 & 2.47 & 4.71 \\
$\quad$ Urbanization $(\%)$ & $\mathrm{UR}$ & 7.89 & 0.01 & 1.12 & 1.41 \\
\hline
\end{tabular}

\subsection{Socioeconomic Factors}

Based on previous research, we selected a wide range of anthropological influencing factors related to $\mathrm{PM}_{2.5}$ concentrations [32-34]. A set of relevant determinants of $\mathrm{PM}_{2.5}$ were selected scientifically and rationally by extending existing analytical frameworks. We examined six variables: economic development, industrial structure, technology innovation, foreign direct investment, government regulation, and urbanization, all of which have been frequently applied to analyze $\mathrm{PM}_{2.5}$ concentrations. First, as a common indicator of 
economic development, the increase in GDP in China has mainly been driven by fossil fuel consumption, which can produce large amounts of air pollution. Second, secondary industry, consisting of both labor-intensive and energy-intensive industries, led to an increase in $\mathrm{PM}_{2.5}$ concentrations. We took the proportion of secondary industry as a proxy for industry structure, which is expected to be positively correlated with $\mathrm{PM}_{2.5}$ concentrations. Third, foreign direct investment has a contentious relationship with $\mathrm{PM}_{2.5}$ concentrations levels. On the one hand, FDI offers low-pollution equipment and technologies and better management, understood to result in reduced emissions. On the other hand, FDI may contribute to increased $\mathrm{PM}_{2.5}$ concentrations according to the pollution haven hypothesis. Next, technological innovation is used because technological progress reduces energy consumption and $\mathrm{PM}_{2.5}$ concentrations. Government regulation also plays an important role in controlling $\mathrm{PM}_{2.5}$ concentrations. The more strict anti-pollution countermeasures carried out by the government, the lower the $\mathrm{PM}_{2.5}$ emissions. In addition, it is generally argued that rapid urbanization may negatively impact ambient air quality because urbanization usually requires more extensive infrastructure and transportation, which fosters more fossil fuel consumption and higher $\mathrm{PM}_{2.5}$ concentration.

Data regarding factors influencing $\mathrm{PM}_{2.5}$ concentrations from 2015 to 2019 were obtained from various sources, including the Beijing Statistical Yearbook, Tianjin Statistical Yearbook, Hebei Statistical Yearbook, China Regional Economic Statistical Yearbook, China Urban Statistical Yearbook, China Science and Technology Statistical Yearbook (CNKI: http: / / data.cnki.net/Yearbook, accessed on 5 January 2022). These indicators are summarized in Table 1.

\section{4. $\mathrm{PM}_{2.5}$ Data}

This paper chose the BTHUA as the study area, with $\mathrm{PM}_{2.5}$ concentration data derived from China's National Environmental Monitoring Centre (http:/ /106.37.208.233:20035/, accessed on 5 January 2022). The data quality control for $\mathrm{PM}_{2.5}$ was performed based on the GB3095-2012 requirements of China's National Ambient Air Quality Standards (AAQS) to validate air pollutant concentration data. In this study, the monitored 24-h averaged $\mathrm{PM}_{2.5}$ concentrations at all the stations in a city represent the polluted level of the city. According to the definition of GB3095-2012, the "daily average" refers to the arithmetic mean of a natural daily 24-h average concentration, while the "monthly average" refers to the arithmetic average of the mean concentrations of each day in a calendar month; the "seasonal average" represents the arithmetic average of the mean concentrations of each day in a calendar quarter, while the "annual (yearly) average" represents the arithmetic average of the mean concentrations of each day in a calendar year; here, spring covers March through May, summer spans June through August, autumn indicates September through November, and winter consists of December, January, and February.

\subsection{Geographically and Temporally Weighted Regression (GTWR) Modeling}

A geographically and temporally weighted regression (GTWR) model was employed to observe the influence of factors on the explained variables by considering the spatial position relationship between variables, which could capture the instability and mutual differences of spatial data; however, the effect of time would be largely ignored. The GTWR is derived from the local spatiotemporal coefficient of the variation model proposed by Huang (2010) [35], which is a spatiotemporal analysis method based on a GWR model incorporated time series and has the advantage of a time-weighted regression (TWR) in identifying temporal effects. Meanwhile, there is no need to consider the problem of a limited quantity of samples. The spatiotemporal weight matrix is constructed according to the three-dimensional coordinates in this model. An analysis region closer to the region defined by the coordinates is defined to have greater weight (including the proximity of time and space) [36]. A spherical region constructed with the analysis region as the sphere's center is used for local regression. Then, the parameter estimates for different regions at different times are considered. This method has been used in several studies. 
Wang et al. (2021) employed the geographically and temporally weighted regression model to analyze the varying importance and spatiotemporal differentiation of the factors influencing ecosystem services in the Pearl River Delta of China [37]. Liang et al. (2019) studied the impact of urbanization factors and subsystems on environmental pollution by using a GTWR model [38]. The exact calculation process is as follows

$$
\begin{gathered}
y_{i}=\beta_{0}\left(\text { long }_{i}, \text { lat }_{i}, t_{i}\right)+\sum_{j}^{n} \beta_{j}\left(\text { long }_{i}, \text { lat }_{i}, t_{i}\right) x_{i j}+\varepsilon_{i} \\
i=1,2,3, \cdots, 13 j=1,2,3, \cdots, n
\end{gathered}
$$

Here, $y_{i}$ is the $\mathrm{PM}_{2.5}$ concentration of city $i, \operatorname{long}_{i}$ is the longitude of the city $i$, lat $_{i}$ is the latitude of the city $i, t_{i}$ is the year of the city $i, \beta_{0}\left(\operatorname{long}_{i}, l a t_{i}, t_{i}\right)$ and $\beta_{j}\left(\operatorname{long}_{i}, l a t_{i}, t_{i}\right)$ are the latitude and longitude function of city $i$, and the parameters to be estimated. The term $x_{i j}$ is the explanatory variable of the city factors to $\mathrm{PM}_{2.5}$, and $\varepsilon_{i} \stackrel{i i d}{\sim} N\left(0, \sigma^{2}\right)$ is the random disturbance term.

The space-time weighted matrix is a key part of GTWR model, and the formulation is: $W\left(\right.$ long $\left._{i}, \operatorname{lat}_{i}, t_{i}\right)=\operatorname{diag}\left(w_{i 1}, w_{i 2}, \cdots, w_{i m}\right), m=1,2,3, \cdots, 13 ; w_{i m}$ is a function based on the space-time distance attenuation

$$
w_{i m}=\exp \left(-\frac{d_{i m}^{2}}{h^{2}}\right)
$$

where $d_{i m}$ is the spatiotemporal distance between $i$ and $m$, and $h^{2}$ is the width of the spatiotemporal window. The term $d_{i m}$ and the minimum cross-verification method is determined by

$$
\begin{gathered}
d_{i m}=\sqrt{\lambda\left[\left(\operatorname{long}_{i}-\operatorname{long}_{m}\right)^{2}+\left(\text { lat }_{i}-l a t_{m}\right)^{2}\right]+\gamma\left(t_{i}-t_{m}\right)^{2}} \\
\operatorname{minCV}=\sum\left[y_{i}-y_{m \neq i}(h)\right]
\end{gathered}
$$

where $\lambda$ determines the spatial distance $\left(\operatorname{long}_{i}-\operatorname{long}_{m}\right)^{2}+\left(l a t_{i}-l a t_{m}\right)^{2}$, when $\lambda=0$ there is no spatial effect; $\gamma$ determines the separation in time $\left(t_{i}-t_{m}\right)^{2}$, when $\gamma=0$ there is no time effect. The GTWR model requires $\lambda \neq 0$ and $\gamma \neq 0 ; h$ is the optimal time-space window width determined by the cross-verification method (CV) by minimizing the sum of the squares of residuals.

Letting $h^{s-t}$ be the width of the space-time window, $h^{s}$ be the width of the spatial window, $h^{t}$ be the width of the time window, and satisfy $h^{s-t}=\lambda h^{s}=\gamma h^{t}$. At this point, substituting Equations (3) and (4) into Equation (2), we obtain

$$
w_{i m}^{s t}=\exp \left[-\frac{\left(\operatorname{long}_{i}-\operatorname{long}_{m}\right)^{2}+\left(\operatorname{lat}_{i}-l a t_{m}\right)^{2}}{\left(h^{s}\right)^{2}}-\frac{\left(t_{i}-t_{m}\right)^{2}}{\left(h^{t}\right)^{2}}\right]
$$

Equation (5) is simplified and can be obtained as follows

$$
w_{i m}^{s t}=w_{i m}^{s t}=\exp \left[-\frac{\left(\operatorname{long}_{i}-\operatorname{long}_{m}\right)^{2}+\left(\text { lat }_{i}-\text { lat }_{m}\right)^{2}}{\left(h^{s}\right)^{2}}\right] * \exp \left[-\frac{\left(t_{i}-t_{m}\right)^{2}}{\left(h^{t}\right)^{2}}\right]=w_{i m}^{s} * w_{i m}^{t}
$$

Bandwidth plays a significant role in the regression results and this paper adopts an adaptive bandwidth and establishes the AICc as its criterion to obtain more accurate analysis, given that excessive bandwidth results in points with little impact in the fitting process, while a bandwidth too small produces overfitting. To facilitate differentiation, this paper divides the influence degree types according to the parameter results and divides the negative and positive influences into low, medium, and high categories, respectively. 


\section{Results}

\subsection{Characteristics of Temporal and Spatial Variation to $P M_{2.5}$}

\subsubsection{Temporal Characteristics}

The $\mathrm{PM}_{2.5}$ concentration measurements covered the five years from 2015 to 2019. Figure 2 shows the 24-h and monthly measurements of $\mathrm{PM}_{2.5}$ concentrations over this time and generally indicates that $\mathrm{PM}_{2.5}$ concentrations remarkably exceeded the Chinese standard of $35 \mu \mathrm{g} / \mathrm{m}^{3}$ (black line). Obviously, more often than not, monthly averages exceeded the standard of $75 \mu \mathrm{g} / \mathrm{m}^{3}$ (blue line). The $\mathrm{PM}_{2.5}$ concentrations achieved their highest level in 2015 before decreasing in the following years. In total, 1325 days out of 1826 days met the criteria, while the remaining 501 days went beyond the criteria, ranging from $35 \mu \mathrm{g} / \mathrm{m}^{3}$ to $310 \mu \mathrm{g} / \mathrm{m}^{3}$. The 24-h averages of $\mathrm{PM}_{2.5}$ displayed cyclic variations over certain time intervals in BTHUA (Figure 2). The average length of a $\mathrm{PM}_{2.5}$ cycle was almost seven days, both in spring and winter, while that of summer and autumn was almost twice as long, about 15 days. The 24-h maximum value occurred on 22 December 2015 at $329.84 \mu \mathrm{g} / \mathrm{m}^{3}$, while the minimum was recorded on 13 August 2019 , at $8.76 \mu \mathrm{g} / \mathrm{m}^{3}$.
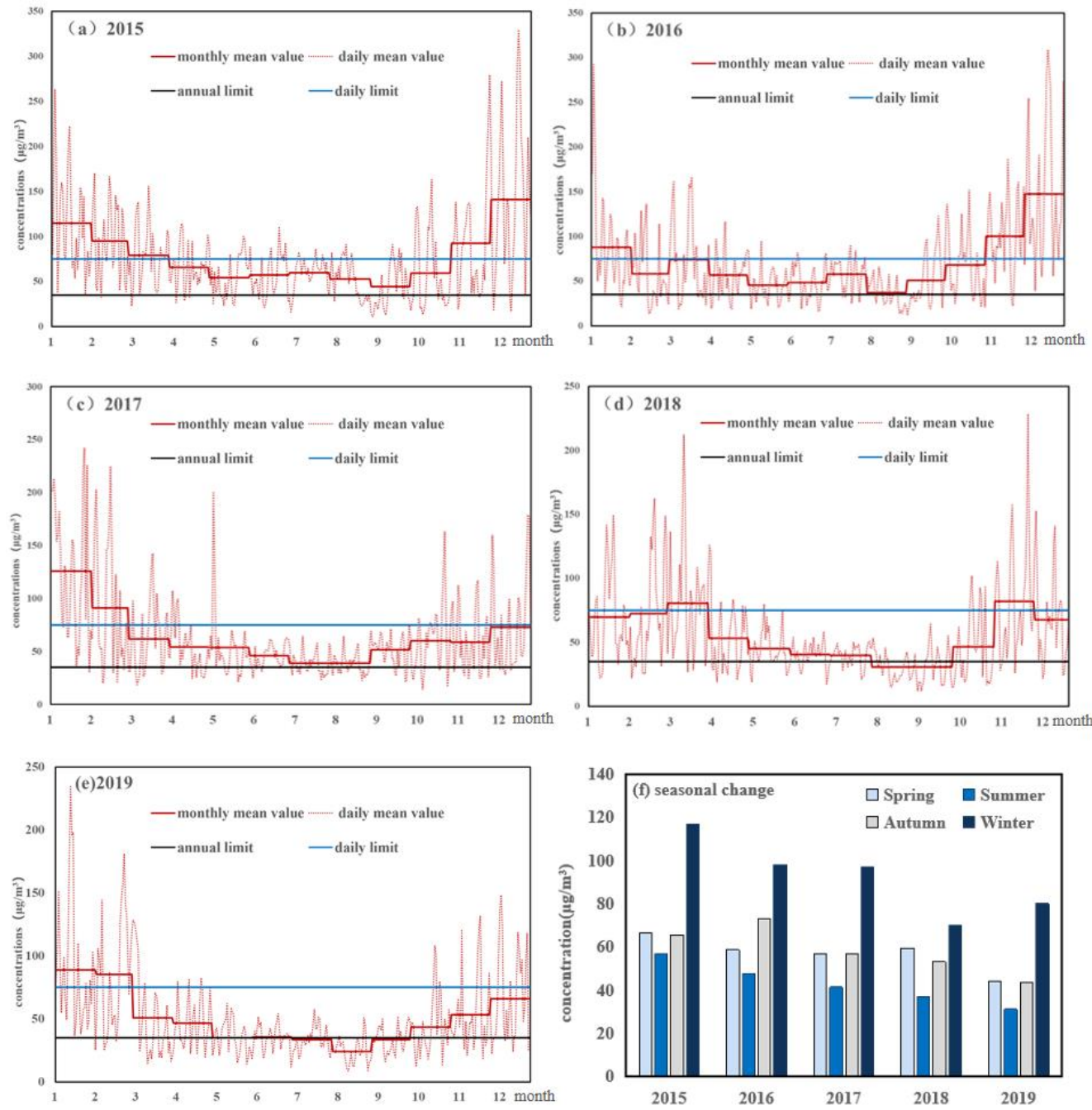

Figure 2. Daily and monthly variations in $\mathrm{PM}_{2.5}$ concentrations in Beijing-Tianjin-Hebei urban agglomeration from 2015 to 2019.

Figure 2 demonstrates the monthly averages of $\mathrm{PM}_{2.5}$ concentration over 12 months for each year from 2015 to 2019, which illustrates distinct variations. The monthly averages were similar in every year and showed a U-shaped pattern. The highest concentration occurred between October and March, and the lowest concentrations were clustered between 
May and September. The highest monthly average value was December, at $99 \mu \mathrm{g} / \mathrm{m}^{3}$. The lowest value was observed in August $\left(36.7 \mu \mathrm{g} / \mathrm{m}^{3}\right)$, still slightly higher than the AAQ standards.

The highest value of $\mathrm{PM}_{2.5}$, with an average value exceeding $92 \mu \mathrm{g} / \mathrm{m}^{3}$, appeared in winter when centralized heating was ongoing. The average value for the winter season was $116.9 \mu \mathrm{g} / \mathrm{m}^{3}$ in 2015, whereas after that year, there was a clear decline that became more profound in 2018 with the lowest value, followed by a slight increase in 2019, with an average value of around $80 \mu \mathrm{g} / \mathrm{m}^{3}$. Autumn and spring ranked second and third with mean values of $58.4 \mu \mathrm{g} / \mathrm{m}^{3}$ and $57.0 \mu \mathrm{g} / \mathrm{m}^{3}$, respectively. The lowest concentrations occurred in summer, with an average value of $42.7 \mu \mathrm{g} / \mathrm{m}^{3}$. Notably, none of the average seasonal values met the Ambient Air Quality Standards (Figure 2f).

\subsubsection{Spatial Change}

Figure 3 shows the markedly changed magnitude and spatial distribution of $\mathrm{PM}_{2.5}$ concentrations in the BTHUA from 2015 to 2019. According to both the World Health Organization (WHO) and China's national ambient air quality standards (AAQA), we established five annual $\mathrm{PM}_{2.5}$ level ranges, including excellent $\left(<15 \mu \mathrm{g} / \mathrm{m}^{3}\right)$, good $\left(15-35 \mu \mathrm{g} / \mathrm{m}^{3}\right)$, slightly polluted $\left(35-50 \mu \mathrm{g} / \mathrm{m}^{3}\right)$, moderately polluted $\left(50-75 \mu \mathrm{g} / \mathrm{m}^{3}\right)$, and heavily polluted $\left(>75 \mu \mathrm{g} / \mathrm{m}^{3}\right)$. As seen in Figure 3, there were no cities with concentrations lower than $15 \mu \mathrm{g} / \mathrm{m}^{3}$ from 2015 to 2019 . In 2015, the areas with heavily polluted levels (i.e., mean annual $\mathrm{PM}_{2.5}>75 \mu \mathrm{g} / \mathrm{m}^{3}$ ) were clustered around the middle and southern part of BTHUA, while the value of $\mathrm{PM}_{2.5}$ concentrations was relatively lower $\left(<50 \mu \mathrm{g} / \mathrm{m}^{3}\right)$ in the northern mountain areas. In 2015, eight cities, including Beijing, Langfang, Tangshan, Baoding, Shijiazhuang, Xingtai, Hengshui, and Handan, exceeded the heavily polluted level, accounting for $72.72 \%$ of the whole area. During 2016 and 2017, Beijing and Tangshan were excluded from the heavily polluted list and, consequently, the number of heavily polluted areas decreased. Compared with previous years, the gap between heavily polluted areas has narrowed between the northern and southern regions since 2018. In other words, $\mathrm{PM}_{2.5}$ concentrations in most of the northern regions increased from "good" or "slightly polluted" to the "moderately polluted" level, while those of the southern regions decreased from "heavily polluted" to the "moderately polluted" level. In particular, Baoding had the lowest $\mathrm{PM}_{2.5}$ concentrations after 2018, which may be due to the national strategic establishment of a "Xiong'An New Area", which, as one of three national strategies, has made Baoding area undertake the important role of the so-called non-capital functions to take over the heavy burdens the capital city of Beijing once bore.

\subsection{Factors Influencing $P M_{2.5}$ Concentrations}

We chose ten variables to determine the mechanisms that influenced the $\mathrm{PM}_{2.5}$ concentrations in BTHUA across the study period. Early studies have clearly established a significant spatial autocorrelation of the $\mathrm{PM}_{2.5}$ distribution in the BTHUA area. The clustering characteristics reflect the spatial spillover effect of $\mathrm{PM}_{2.5}$ concentrations, meaning that local $\mathrm{PM}_{2.5}$ pollution can positively impact concentrations in adjacent areas [39,40]. The GTWR model was extended from a GWR model to take temporal variations into consideration, allowing significantly better goodness of fit than that of conventional least square methods and GWR models [20]. To explore the spatial and temporal non-stationary nature of the mechanism, a geographic and time-weighted regression (GTWR) model was constructed to analyze the spatial and temporal differentiation of the influencing factors from 2015 to 2019. The results from Table 2 showed that, in comparison with OLS and GWR, the AICc value of GTWR produced better fitting effects with decreases by 69.54 and 17.92 , and $R^{2}$ increases by 0.125 and 0.027 , respectively. The test suggested that the GTWR model performed better than the global OLS and GWR model. When analyzing the influencing factors of $\mathrm{PM}_{2.5}$ concentrations, the GTWR model containing spatial and temporal heterogeneity is more compatible than the OLS model, which focuses only on global regression and the GWR model without any time effects. 


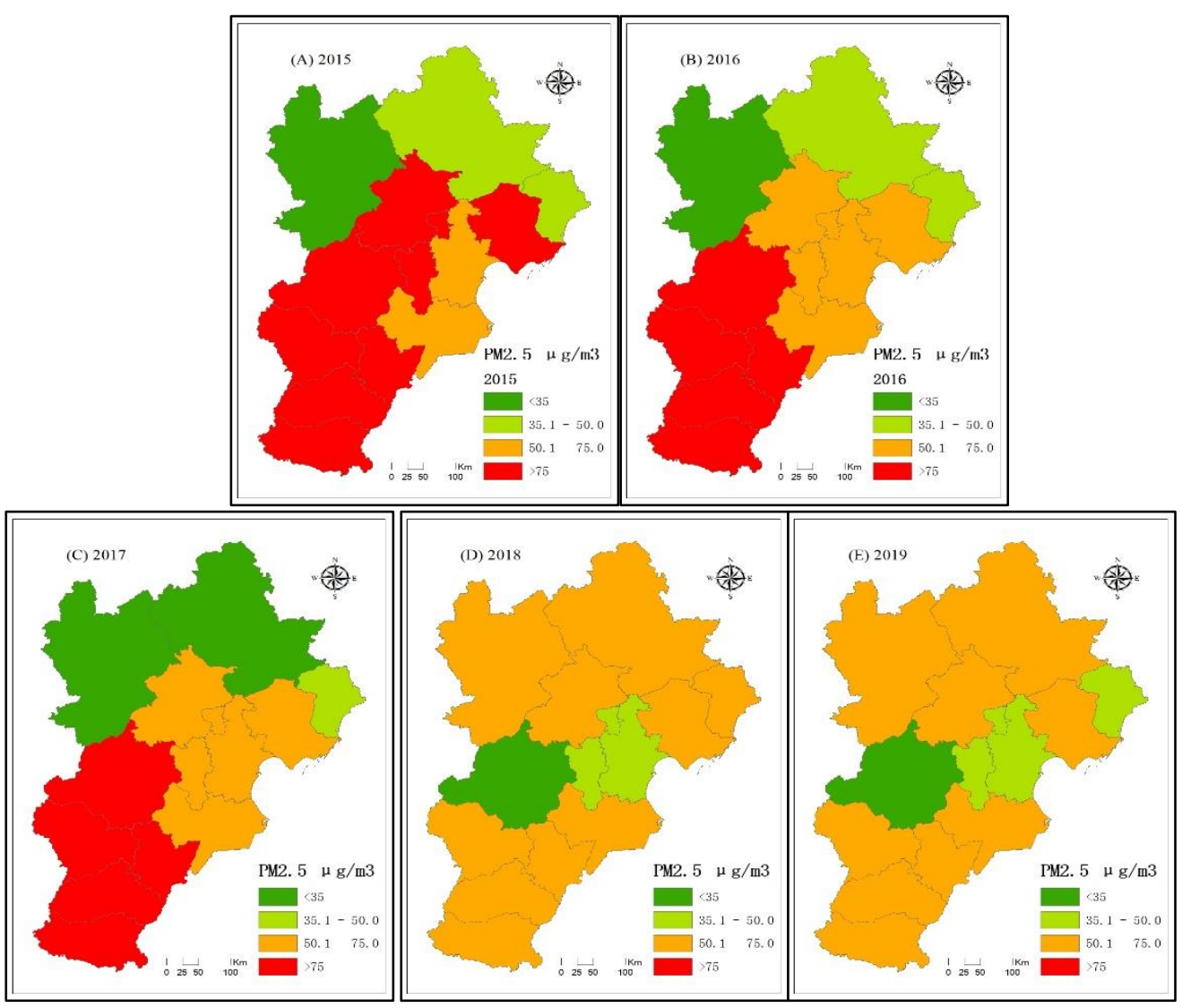

Figure 3. Spatial distribution of $\mathrm{PM}_{2.5}$ concentrations in the Beijing-Tianjin-Hebei urban agglomeration from 2015 to 2019.

Table 2. Assessment of GTWR model.

\begin{tabular}{cccccc}
\hline Indicator & \multicolumn{3}{c}{ Model Type } & \multicolumn{2}{c}{ Model Comparison } \\
\hline & OLS & GWR & GTWR & GTWR-OLS & GTWR-GWR \\
\hline AICc & 339.27 & 287.65 & 269.73 & -69.54 & -17.92 \\
$\mathrm{R}^{2}$ & 0.823 & 0.921 & 0.948 & 0.125 & 0.027 \\
\hline
\end{tabular}

\subsubsection{Natural Factors Influencing $\mathrm{PM}_{2.5}$ Concentrations}

Figure 4 shows the spatial differences present in the coefficients of the natural factors addressed in the BTHUA. The results indicate a negative regression coefficient between rainfall and $\mathrm{PM}_{2.5}$ concentrations. The negative regression coefficient between the wind speed and $\mathrm{PM}_{2.5}$ concentrations was about $92.31 \%$. In most cities, the factor of relative humidity correlated positively with $\mathrm{PM}_{2.5}$ concentrations $(92.31 \%)$. In contrast, the temperature factor displayed a negative relationship with $\mathrm{PM}_{2.5}$ concentrations (61.54\%).

\subsubsection{Socioeconomic Factors Influencing $\mathrm{PM}_{2.5}$ Concentrations}

Figure 5 illustrates the geographic distribution of the regression coefficient values for the socioeconomic factors of this study. Previous research has highlighted the GDP and industry structure as significant factors affecting $\mathrm{PM}_{2.5}$ concentrations. Data analysis revealed a positive correlation coefficient between GDP and $\mathrm{PM}_{2.5}$ concentrations of about $92.31 \%$ for this area. The regression results for the GTWR show that the positive regression coefficient between the space proportion dedicated to industrial structures and $\mathrm{PM}_{2.5}$ is about $69.23 \%$. The area of BTHUA with a positive correlation coefficient between the urbanization factor and $\mathrm{PM}_{2.5}$ concentrations accounted for about $76.92 \%$ of the total area. 


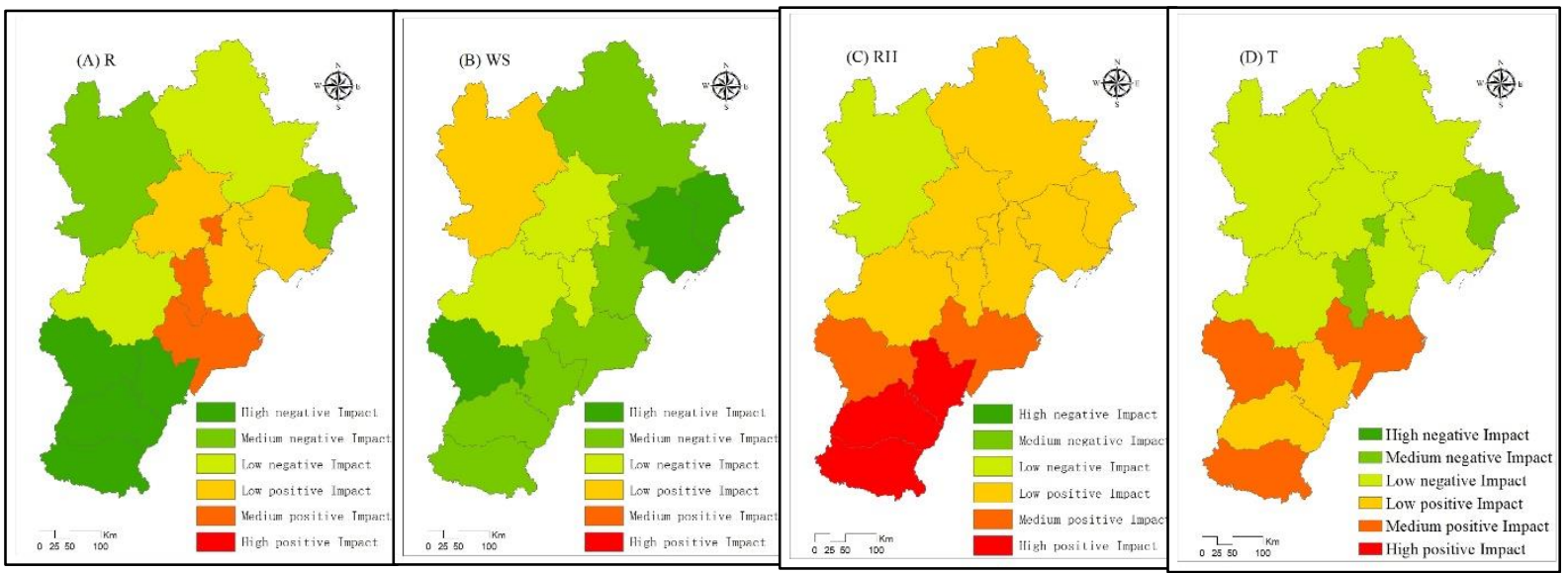

Figure 4. Spatial distribution of regression coefficients for natural factors in the Beijing-Tianjin-Hebei urban agglomeration during the study period.
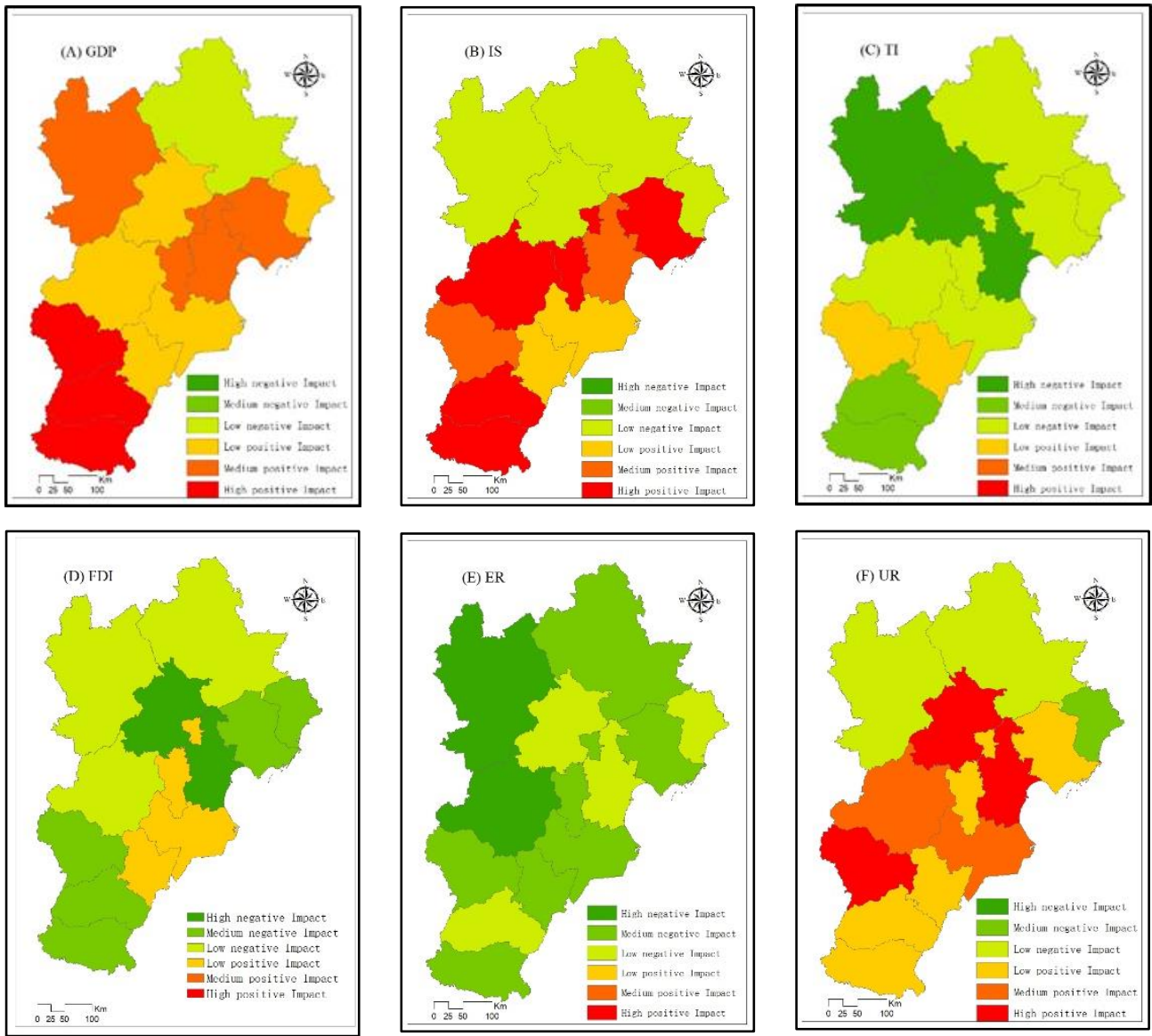

Figure 5. Spatial distribution of regression coefficients for socioeconomic factors in the BeijingTianjin-Hebei urban agglomeration during the study period.

About $84.62 \%$ of the area in the BTHUA was characterized by negative correlation coefficients between the technology innovation factor and $\mathrm{PM}_{2.5}$ concentrations. The total effect of foreign direct investment on $\mathrm{PM}_{2.5}$ concentrations is also proven to be negative, with a regression coefficient of $76.92 \%$, the reason for which may be interpreted by the pollution halo hypothesis. The environmental regulation factor in the BTHUA demonstrated a distinct negative correlation with $\mathrm{PM}_{2.5}$ concentrations, which was consistent with both initial predictions and common sense. 


\section{Discussion}

Our results indicate significant spatial heterogeneity in both the direction and strength of the determinants at the local scale. In the southern part of the BTHUA, such as the cities of Shijiazhuang, Xingtai, Handan, $\mathrm{PM}_{2.5}$ concentrations had a high positive correlation with economic growth (Figure 5a). According to the environmental Kuznets curve, economic development can, in its later stages, be harmful to the environment because it consumes large amounts of resources and energy. It seems paradoxical that a mutualistic relationship between China's economic growth and environmental pollution has likely long existed until the BTHUA broke through the inflection point of the environmental Kuznets curve [41].

The $\mathrm{PM}_{2.5}$ concentrations showed strong positive correlations with the secondary industrial structure (Figure 5b). The economy in the four areas of Tianjin, Tangshan, Shijiazhuang, and Xingtai was driven mainly by heavy industries such as steel, automobile, and equipment manufacturing facilities, characterized by high resource consumption. Heavy industry served as the chief source of $\mathrm{PM}_{2.5}$ concentrations in these areas. On the contrary, the industrial structure of Zhangjiakou, Chengde, Qinhuangdao, and Beijing in the north correlated negatively with the concentrations of $\mathrm{PM}_{2.5}$. The reason lies within the fact that the main industrial structure of these places is dominated by the service industry, with relatively less pollution from industrial activities. For example, Beijing is famous for its tertiary and technology-intensive industries, both of which are classified as service industries resulting in less energy consumption. As an ecological barrier of the BeijingTianjin-Hebei urban agglomeration, the northern mountainous area has emphasized the development of the tourism-driven industry. Therefore, we can conclude that different industrial structures produce different effects on the environmental quality of cities.

Technology innovation was negatively correlated with $\mathrm{PM}_{2.5}$ concentrations (Figure 5c). For one, this may be due to the continuous creation of new technologies and products that are more environmentally friendly and efficient to both economic activities and daily life. For another, the pollution prevention technology in China is becoming more advanced so that air pollution can be better controlled. In megacities such as Beijing and Tianjin, where there is a tremendous emphasis on scientific research and technological improvements, more and more technicians and workers are receiving high-level technical education, which tends to explain the strong negative correlation between technical innovation levels and $\mathrm{PM}_{2.5}$ concentrations. In contrast, the TI levels of Shijiazhuang, which is in the transformation stage of the pollution industry, and Hengshui, which is lagging in technological innovation because of its relatively poor economic development, have a positive correlation with $\mathrm{PM}_{2.5}$ concentration, indicating that its technological achievement may not, as of yet, have been transformed into actual ecological benefits.

The foreign direct investment significantly reduces $\mathrm{PM}_{2.5}$ concentrations, especially if the FDI is accompanied by advanced technologies, which would tend to create spillovers for domestic industries. Beijing and Tianjin showed large negative coefficients between FDI and $\mathrm{PM}_{2.5}$ concentrations (Figure 5d). Wang et al. (2020) researched 18 urban agglomerations in China and found that FDI had a negative impact on the BTHUA, which is consistent with the research results of this paper [42].

The environmental regulation factor in the BTHUA showed a distinct negative correlation with $\mathrm{PM}_{2.5}$ concentrations (Figure 5e). This conclusion is further evidenced in the goalsetting of "constructing ecological civilization," a section of the report by the 18th National Congress of the Communist Party of China (CPC). Consequently, government regulators began to take powerful measures to enhance economic and social transformation based on the efficient use of resources and establishing green, low-carbon growth, upgrading production, and changing lifestyles to achieve the goal of green development. Qu (2020) pointed out that the aggressive abatement policies likely contributed to reductions in normalized $\mathrm{PM}_{2.5}$ concentrations [43].

The positive coefficients of megacities and big cities such as Beijing, Tianjin, and Shijiazhuang are high, which indicates that the intensive urbanization in these areas intensifies environmental pollution (Figure 5f). Negative coefficients between urbanization and 
$\mathrm{PM}_{2.5}$ emerged mainly in the northern mountainous areas. We can conclude that suitable urbanization in mountainous areas in its early stages effectively contributes to improving environmental quality. This conclusion is consistent with the research findings of Liang et al. (2019) and confirms that the impact mechanism of urbanization on $\mathrm{PM}_{2.5}$ pollution varies with the level of urban development [38].

\section{Conclusions}

This research set out to discover the key effective influencing factors contributing to $\mathrm{PM}_{2.5}$ in BTHUA. We analyzed the spatiotemporal change in $\mathrm{PM}_{2.5}$ concentrations in the Beijing-Tianjin-Hebei urban agglomeration (BTHUA). We found that the $\mathrm{PM}_{2.5}$ pollution showed an overall decreasing trend from 2015 to 2019 and the spatial gap between the north and the south decreased in recent years.

This study creatively applied an improved GWR model to a designated region so as to estimate the association between $\mathrm{PM}_{2.5}$ concentrations and a series of key socioeconomic and meteorological factors. The GTWR model was extended from a GWR model by adding temporal variations, and the added complexity of the GTWR model produced significantly better goodness of fit than that of conventional OLS methods and GWR models. The GTWR performed in this study is helpful in recognizing the effects of influencing factors varying in time and space.

The findings of this study provide detailed empirical evidence for regions to improve air quality in accordance with local conditions. Moreover, this study contributes valuable insights to visualizing those spatial and temporal variations in the correlation coefficients of each determinant related to $\mathrm{PM}_{2.5}$ concentrations. This visualization may help local policymakers adopt specific policies in accordance with local pollution patterns and corresponding development models, as opposed to a "one-size fits all" approach. Additionally, the cities of BTHUA should scientifically adjust industrial structures, implement the optimization and upgrading of economic growth, maximize the efficiency of energy use, implement strict environmental access standards, and define a bottom line for ecological protection.

However, there are two limitations in this paper. Due to the limited data of the socioeconomic factors, taking a city as the basic research unit restrained the choices of factor variables and further deep explorations. Future improvement should be directed to lower-level administrative regions as its basic research unit. In addition, this paper adopted the GTWR model that captures the spatial variations in regression coefficients for different research units and allows the spatiotemporal disparities. Although it has been previously used, there are still some uncertainties in its objectivity and timeliness. Hybrid deep learning methodologies such as random forest regression should be proposed in the future.

Author Contributions: Conceptualization, Q.L. and H.L.; methodology, X.L. and Q.L.; validation, Q.L. and H.L.; writing—original draft preparation, Q.L. and X.L.; writing—review and editing, Q.L. and X.L. All authors have read and agreed to the published version of the manuscript.

Funding: The research was supported by National Natural Science Foundation of China No. 41771181.

Informed Consent Statement: Not applicable.

Data Availability Statement: Not applicable.

Conflicts of Interest: The authors declare no conflict of interest.

\section{References}

1. Rohde, R.A.; Muller, R.A. Air Pollution in China: Mapping of Concentrations and Sources. PLoS ONE 2015, 10, e0135749. [CrossRef]

2. Pey, J.; Alastuey, A.; Querol, X. $\mathrm{PM}_{10}$ and $\mathrm{PM}_{2.5}$ sources at an insular location in the western Mediterranean by using source apportionment techniques. Sci. Total Environ. 2013, 456, 267-277. [CrossRef] [PubMed] 
3. Wang, Z. Satellite-Observed Effects from Ozone Pollution and Climate Change on Growing-Season Vegetation Activity over China during 1982-2020. Atmosphere 2021, 12, 1390. [CrossRef]

4. Lee, J.Y.; Jo, W.K.; Chun, H.-H. Long-Term Trends in Visibility and Its Relationship with Mortality, Air-Quality Index, and Meteorological Factors in Selected Areas of Korea. Aerosol Air Qual. Res. 2015, 15, 673-681. [CrossRef]

5. Wang, Z.B.; Fang, C.L. Spatial-temporal characteristics and determinants of $\mathrm{PM}_{2.5}$ in the Bohai Rim Urban Agglomeration. Chemosphere 2016, 148, 148-162. [CrossRef]

6. Hajiloo, F.; Hamzeh, S.; Gheysari, M. Impact assessment of meteorological and environmental parameters on $\mathrm{PM}_{2.5}$ concentrations using remote sensing data and GWR analysis (case study of Tehran). Environ. Sci. Pollut. Res. 2019, 26, 24331-24345. [CrossRef] [PubMed]

7. Jedruszkiewicz, J.; Czernecki, B.; Marosz, M. The variability of $\mathrm{PM}_{10}$ and $\mathrm{PM}_{2.5}$ concentrations in selected Polish agglomerations: The role of meteorological conditions, 2006-2016. Int. J. Environ. Health Res. 2017, 27, 441-462. [CrossRef]

8. Li, W.G.; Duan, F.K.; Zhao, Q.; Song, W.W.; Cheng, Y.; Wang, X.Y.; Li, L.; He, K.B. Investigating the effect of sources and meteorological conditions on wintertime haze formation in Northeast China: A case study in Harbin. Sci. Total Environ. 2021, 801, 149631. [CrossRef]

9. Wang, Q.; Kwan, M.P.; Zhou, K.; Fan, J.; Wang, Y.F.; Zhan, D.S. The impacts of urbanization on fine particulate matter (PM 2.5$)$ concentrations: Empirical evidence from 135 countries worldwide. Environ. Pollut. 2019, 247, 989-998. [CrossRef]

10. Zhou, C.S.; Wang, S.J.; Wang, J.Y. Examining the influences of urbanization on carbon dioxide emissions in the Yangtze River Delta, China: Kuznets curve relationship. Sci. Total Environ. 2019, 675, 472-482. [CrossRef]

11. $\mathrm{Wu}, \mathrm{W}$.; Zhang, M.; Ding, Y. Exploring the effect of economic and environment factors on $\mathrm{PM}_{2.5}$ concentration: A case study of the Beijing-Tianjin-Hebei region. J. Environ. Manag. 2020, 268, 110703. [CrossRef]

12. Wolde-Rufael, Y.; Idowu, S. Income distribution and $\mathrm{CO}_{2}$ emission: A comparative analysis for China and India. Renew. Sustain. Energy Rev. 2017, 74, 1336-1345. [CrossRef]

13. Wu, S.W.; Deng, F.R.; Niu, J.; Huang, Q.S.; Liu, Y.C.; Guo, X.B. Association of Heart Rate Variability in Taxi Drivers with Marked Changes in Particulate Air Pollution in Beijing in 2008. Environ. Health Perspect. 2010, 118, 87-91. [CrossRef] [PubMed]

14. Xie, Z.; Li, Y.; Qin, Y. Allocation of control targets for $\mathrm{PM}_{2.5}$ concentration: An empirical study from cities of atmospheric pollution transmission channel in the Beijing-Tianjin-Hebei district. J. Clean. Prod. 2020, 270, 122545. [CrossRef]

15. Zoundi, Z. $\mathrm{CO}_{2}$ emissions, renewable energy and the Environmental Kuznets Curve, a panel cointegration approach. Renew. Sustain. Energy Rev. 2017, 72, 1067-1075. [CrossRef]

16. Al-mulali, U.; Tang, C.F. Investigating the validity of pollution haven hypothesis in the gulf cooperation council (GCC) countries. Energy Policy 2013, 60, 813-819. [CrossRef]

17. Wang, S.J.; Liu, X.P.; Zhou, C.S.; Hu, J.C.; Ou, J.P. Examining the impacts of socioeconomic factors, urban form, and transportation networks on $\mathrm{CO}_{2}$ emissions in China's megacities. Appl. Energy 2017, 185, 189-200. [CrossRef]

18. Lou, C.R.; Liu, H.Y.; Li, Y.F.; Li, Y.L. Socioeconomic Drivers of $\mathrm{PM}_{2.5}$ in the Accumulation Phase of Air Pollution Episodes in the Yangtze River Delta of China. Int. J. Environ. Res. Public Health 2016, 13, 928. [CrossRef]

19. Zhan, D.; Kwan, M.-P.; Zhang, W.; Yu, X.; Meng, B.; Liu, Q. The driving factors of air quality index in China. J. Clean. Prod. 2018, 197, 1342-1351. [CrossRef]

20. Liu, Q.Q.; Wu, R.; Zhang, W.Z.; Li, W.; Wang, S.J. The varying driving forces of $\mathrm{PM}_{2.5}$ concentrations in Chinese cities: Insights from a geographically and temporally weighted regression model. Environ. Int. 2020, 145, 106168. [CrossRef]

21. Li, G.D.; Fang, C.L.; Wang, S.J.; Sun, S. The Effect of Economic Growth, Urbanization, and Industrialization on Fine Particulate Matter $\left(\mathrm{PM}_{2.5}\right)$ Concentrations in China. Environ. Sci. Technol. 2016, 50, 11452-11459. [CrossRef] [PubMed]

22. Wang, J.Y.; Wang, S.J.; Li, S.J. Examining the spatially varying effects of factors on PM2.5 concentrations in Chinese cities using geographically weighted regression modeling. Environ. Pollut. 2019, 248, 792-803. [CrossRef] [PubMed]

23. Akbal, Y.; Ünlü, K.D. A deep learning approach to model daily particular matter of Ankara: Key features and forecasting. Int. J. Environ. Sci. Technol. 2021, 1-17. [CrossRef]

24. Akdi, Y.; Gölveren, E.; Ünlü, K.D.; Yücel, M.E. Modeling and forecasting of monthly $\mathrm{PM}_{2.5}$ emission of Paris by periodogram-based time series methodology. Environ. Monit. Assess. 2021, 193, 622. [CrossRef]

25. $\mathrm{Xu}, \mathrm{B}$; $\mathrm{Lin}, \mathrm{B} . \mathrm{Q}$. What cause large regional differences in $\mathrm{PM}_{2.5}$ pollutions in China? Evidence from quantile regression model. J. Clean. Prod. 2018, 174, 447-461. [CrossRef]

26. Li, X.Y.; Song, H.Q.; Zhai, S.Y.; Lu, S.Q.; Kong, Y.F.; Xia, H.M.; Zhao, H.P. Particulate matter pollution in Chinese cities: Arealtemporal variations and their relationships with meteorological conditions (2015-2017). Environ. Pollut. 2019, 246, 11-18. [CrossRef]

27. Wang, J.; Ogawa, S. Effects of Meteorological Conditions on $\mathrm{PM}_{2.5}$ Concentrations in Nagasaki, Japan. Int. J. Environ. Res. Public Health 2015, 12, 9089-9101. [CrossRef]

28. Park, I.S.; Kim, S.H.; Jang, Y.W.; Park, M.S.; Lee, J.; Owen, J.S.; Cho, C.R.; Jee, J.B.; Chae, J.H.; Kang, M.S. Meteorological Characteristics during Periods of Greatly Reduced PM 2.5 Concentrations in March 2020 in Seoul. Aerosol Air Qual. Res. 2021, 21, 200512. [CrossRef]

29. Pateraki, S.; Asimakopoulos, D.N.; Flocas, H.A.; Maggos, T.; Vasilakos, C. The role of meteorology on different sized aerosol fractions. Sci. Total Environ. 2012, 419, 124-135. [CrossRef] 
30. Tai, A.P.K.; Mickley, L.J.; Jacob, D.J. Correlations between fine particulate matter $\left(\mathrm{PM}_{2.5}\right)$ and meteorological variables in the United States: Implications for the sensitivity of $\mathrm{PM}_{2.5}$ to climate change. Atmos. Environ. 2010, 44, 3976-3984. [CrossRef]

31. Li, L.; Qian, J.; Ou, C.Q.; Zhou, Y.X.; Guo, C.; Guo, Y.M. Spatial and temporal analysis of Air Pollution Index and its timescaledependent relationship with meteorological factors in Guangzhou, China, 2001-2011. Environ. Pollut. 2014, 190, 75-81. [CrossRef] [PubMed]

32. Yang, Q.Q.; Yuan, Q.Q.; Li, T.W.; Shen, H.F.; Zhang, L.P. The Relationships between $\mathrm{PM}_{2.5}$ and Meteorological Factors in China: Seasonal and Regional Variations. Int. J. Environ. Res. Public Health 2017, 14, 1510. [CrossRef]

33. Masiol, M.; Hopke, P.K.; Felton, H.D.; Frank, B.P.; Rattigan, O.V.; Wurth, M.J.; LaDuke, G.H. Source apportionment of PM 2.5 chemically speciated mass and particle number concentrations in New York City. Atmos. Environ. 2017, 148, 215-229. [CrossRef]

34. Hao, Y.; Liu, Y.-M. The influential factors of urban $\mathrm{PM}_{2.5}$ concentrations in China: A spatial econometric analysis. J. Clean. Prod. 2016, 112, 1443-1453. [CrossRef]

35. Chen, J.; Zhou, C.; Wang, S.; Hu, J. Identifying the socioeconomic determinants of population exposure to particulate matter $\left(\mathrm{PM}_{2.5}\right)$ in China using geographically weighted regression modeling. Environ. Pollut. 2018, 241, 494-503. [CrossRef] [PubMed]

36. Huang, B.; Wu, B.; Barry, M. Geographically and temporally weighted regression for modeling spatio-temporal variation in house prices. Int. J. Geogr. Inf. Sci. 2010, 24, 383-401. [CrossRef]

37. Wu, S.S.; Wang, Z.Y.; Du, Z.H.; Huang, B.; Zhang, F.; Liu, R.Y. Geographically and temporally neural network weighted regression for modeling spatiotemporal non-stationary relationships. Int. J. Geogr. Inf. Sci. 2021, 35, 582-608. [CrossRef]

38. Wang, S.J.; Liu, Z.T.; Chen, Y.X.; Fang, C.L. Factors influencing ecosystem services in the Pearl River Delta, China: Spatiotemporal differentiation and varying importance. Resour. Conserv. Recycl. 2021, 168, 105477. [CrossRef]

39. Liang, L.W.; Wang, Z.B.; Li, J.X. The effect of urbanization on environmental pollution in rapidly developing urban agglomerations. J. Clean. Prod. 2019, 237, 117649. [CrossRef]

40. Huang, Q.Y.; Chen, G.D.; Xu, C.; Jiang, W.Y.; Su, M.R. Spatial Variation of the Effect of Multidimensional Urbanization on $\mathrm{PM}_{2.5}$ Concentration in the Beijing-Tianjin-Hebei (BTH) Urban Agglomeration. Int. J. Environ. Res. Public Health 2021, $18,2077$. [CrossRef] [PubMed]

41. Li, H.J.; Qi, Y.J.; Li, C.; Liu, X.Y. Routes and clustering features of $\mathrm{PM}_{2.5}$ spillover within the Jing-Jin-Ji region at multiple timescales identified using complex network-based methods. J. Clean. Prod. 2019, 209, 1195-1205. [CrossRef]

42. Shahbaz, M.; Khraief, N.; Uddin, G.S.; Ozturk, I. Environmental Kuznets curve in an open economy: A bounds testing and causality analysis for Tunisia. Renew. Sustain. Energy Rev. 2014, 34, 325-336. [CrossRef]

43. Wang, Z.B.; Li, J.X.; Liang, L.W. Spatio-temporal evolution of ozone pollution and its influencing factors in the Beijing-TianjinHebei Urban Agglomeration. Environ. Pollut. 2020, 256, 113419. [CrossRef] 